Review Article

\title{
Sailing through the COVID-19 Crisis by Using AI for Financial Market Predictions
}

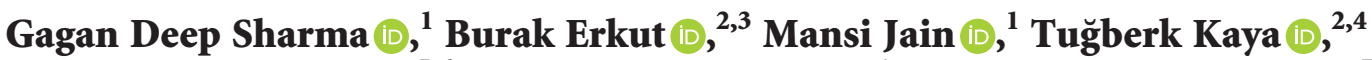 \\ Mandeep Mahendru $\mathbb{D}^{\mathbb{D}},{ }^{5,6}$ Mrinalini Srivastava $\mathbb{D}^{1},{ }^{1}$ Raminder Singh Uppal $\mathbb{D}{ }^{7}$ \\ and Sanjeet Singh $\mathbb{D}^{8}$ \\ ${ }^{1}$ University School of Management Studies, Guru Gobind Singh Indraprastha University, Sector 16C, Dwarka, \\ New Delhi 110078, India \\ ${ }^{2}$ Institute for Research in Economic and Fiscal Issues, Paris 75017, France \\ ${ }^{3}$ Department of Business Administration, Faculty of Economics, Administrative and Social Sciences, \\ Bahcesehir Cyprus University, Nicosia 99010, Northern Cyprus, Turkey \\ ${ }^{4}$ Department of Management Information Systems, School of Applied Sciences, Cyprus International University, Nicosia, \\ Northern Cyprus, Turkey \\ ${ }^{5}$ State Bank Institute of Credit and Risk Management, Gurugram, Haryana, India \\ ${ }^{6}$ State Bank Institute of Leadership, Kolkata, West Bengal, India \\ ${ }^{7}$ BBSBE College, Fatehgarh Sahib 140407, Punjab, India \\ ${ }^{8}$ Chandigarh University, Gharuan 140413, Punjab, India
}

Correspondence should be addressed to Raminder Singh Uppal; rsuppal@gmail.com

Received 22 July 2020; Revised 11 November 2020; Accepted 16 December 2020; Published 30 December 2020

Academic Editor: Manjit Kaur

Copyright (c) 2020 Gagan Deep Sharma et al. This is an open access article distributed under the Creative Commons Attribution License, which permits unrestricted use, distribution, and reproduction in any medium, provided the original work is properly cited.

\begin{abstract}
The outbreak of COVID-19 has brought the world to an unprecedented position where financial and mental resources are drying up. Livelihoods are being lost, and it is becoming tough to save lives. These are the times to think of unprecedented solutions to the financial challenges being faced. Artificial intelligence (AI) has provided a fresh approach to finance through its implementation in the prediction of financial market prices by promising more generalizable results for stock market forecasting. Immense literature has attempted to apply AI and machine learning for predicting stock market returns and volatilities. The research on the applications of AI in finance lacks a consolidated overview of different research directions, findings, methodological approaches, and contributions. Therefore, there is a need to consolidate the extant literature in this upcoming field to consolidate the findings, identify the research gaps in the existing literature, and set a research agenda for future researchers. This paper addresses this need by synthesizing the extant literature in the form of a systematic review for addressing the use of AI in stock market predictions and interpreting the results in a narrative review. The gap formed through this article is the use of a combination of AI as a subject with the neural network as another area and stock market forecasting as another theme, and it will pave the way for future research studies. The analyses help highlight four important gaps in the existing literature on the subject.
\end{abstract}

\section{Introduction}

The world is facing an unprecedented situation with the outbreak of COVID-19 across the globe. Locking down the economies has emerged as a prominent measure to contain the spread of the coronavirus but leads to the loss of livelihoods, nevertheless. Whether or not to impose lockdown is the dilemma of saving lives versus livelihoods [1]. Recent empirical evidence shows that fake news associated with COVID-19 leads to panic, distrust, and confusion, whereas isolation leads to confusion in the thoughts of individuals [2]. Policymakers worldwide are choosing from these two choices of imposing 
lockdown or not, depending upon their demographics, economic situation, medical infrastructure, and social dynamics $[3,4]$. The psychological effects of the crisis affect people's capacity to make prudent financial and nonfinancial decisions [5-7]. This unprecedented crisis calls for unusual solutions to help sustain people's well-being. Using techniques such as artificial intelligence for predictions is emerging as one key idea in such a situation.

Complex economic relations and models and high-frequency events in ever-evolving markets make propagating linear relations amongst economic and financial variables outdated $[8,9]$. For estimating complex nonlinear relations and predicting stock market returns, computer science and econometric analysis go hand in hand. Advancements in computing technologies and econometric methodologies are changing the face of stock market predictions in recent times. Typically, econometric modeling, such as autoregressive (AR), moving average (MA), autoregressive moving average (ARMA), autoregressive integrated moving average (ARIMA), generalized autoregressive conditional heteroskedasticity (GARCH) model, buying and hold (B and $\mathrm{H}$ ) strategy, random walk (RW), stochastic volatility (SV) model, has been employed for predicting stock returns [10], which is now being complemented by artificial intelligence and machine learning systems including artificial neural networks (ANNs), multilayer perceptron (MLP), fuzzy inference systems (FIS), adaptive neuro-fuzzy inference systems (ANFIS), and support vector modeling $[11,12]$.

Artificial neural networks (ANNs) can be considered as neural networks replicated in vitro. A neural network is a meshwork of billions of neurons (cells which are the basic unit of the nervous system) that are involved in processing information. ANNs are analogous to these neural structures as input is required with an optimum amount of threshold to process the inputs and provide a relevant output [13]. Within the neural framework, each neuron carries a weighted combination of many input signals, which is further converted to the activation threshold, and ultimately, an output is generated. Likewise, it is the nature of ANNs where many input signals are combined as a weighted input signal and are transformed as output after the mathematical calculation of all the input signals. The structure of MLP is a three-layered network with an input layer, hidden layer, and output layer [14], which utilizes a backpropagation algorithm for learning. Various algorithms, such as fuzzy logic (FL), probabilistic reasoning (PR), neural networks (NNs), and genetic algorithms (GAs), can be used in symbiotic association in soft computing to solve complex problems of the real world [15].

Artificial intelligence has provided a new and fresh approach to finance through its implementation in the prediction of financial market prices by promising more generalizable results for stock market forecasting. Immense literature has attempted to apply artificial intelligence and machine learning for predicting stock market returns and volatilities [13, 16-45]. Nevertheless, the research on the applications of artificial intelligence in finance lacks a consolidated overview of different research directions, findings, methodological approaches, and contributions. Therefore, there is a need to consolidate the extant literature in this upcoming field to consolidate the findings, identify the research gaps in the existing literature, and set a research agenda for future researchers. This paper addresses this need by synthesizing the extant literature in the form of a systematic review for addressing the use of AI in stock market predictions and interpreting the results in a narrative review.

This paper provides a new outlook on the conceptual synthesis of the extant literature. The researchers can further utilize the existing studies for developing more complex models using machine learning (ML) techniques for forecasting returns, modeling risk, and portfolio construction. The complexity of the nonlinear data can better be served with ML techniques. Multiple-layer perceptron (MLP), support vector machine (SVM), and long short-term memory (LSTM) model are the methods used for quantitative finance. A combination of these methods for deep belief networks and extreme learning machines can predict stocks more accurately [46]. The authors have resolved the conceptual way of explaining the need for more research work in deep learning for advancement in prediction modeling in financial markets. Chatrabgoun et al. [47] explain the use of the Bayesian network with pair-copula construction (BN-PCC) for tackling the issue of heavy tail data in financial applications [48].

Big data in recent times is providing more nonlinear datasets, which can be computed through the use of the ML technique. Furthermore, decision-making involves controlling the variables, which leads to uncertainty for allowing more accurate forecasts in financial markets. Thus, this study serves well by providing an account of variables associated with market prediction and the methodology used to study them, such as hybrid models [49]. However, this becomes pertinent that the models used in the previous studies shall be reinvigorated for their application on nonlinear datasets presented by big data. Techniques such as MLP, SVM, and LSTM can be rekindled with sentiment and emotional analysis for deep learning and prediction accuracy. This paper contributes to the literature in a more unified way by conceptualizing the extant literature and its major findings and methodology implemented for paving the way to future researchers to develop advanced prediction models and frameworks for understanding the variables related to uncertainty in the markets for accuracy in financial market forecasting.

The rest of the paper is organized as follows. In Section 2, the research questions briefly discussed in the introductory section are formulated, and the methodology is introduced. Section 3 presents the findings, where the authors introduce the paradigms associated with artificial intelligence and its use in the predictions of stock behavior under the sections named as descriptive findings. Section 4 involves thematic discussions, whereas Section 5 drives some insights concerning future research and practice.

\section{Materials and Methods}

2.1. Research Questions. Liberalization of the financial markets, along with the developments in strong communications and trading facilities [50], has led to a variety of investment alternatives. While the financial markets of the 
developed nations are highly integrated, the conventional capital markets theory has also evolved, and the financial analysis techniques have upgraded considerably [51].

With the important changes taking place over the last two decades in international finance, most of the financial markets are highly embraced now. The authors in [52] use the daily historical price of the North American stock index DJI and Nasdaq (USA), IPC (Mexico), and TSE (Canada) to foresee the stock indices' sign variations by implementing the logic models and fuzzy logic models which provided favorable returns when used as a trading strategy. Additionally, O'Connor and Madden [53] assess the magnitude of the impact of using external indicators such as commodity prices and currency exchange rates in predicting movements in the Dow Jones Industrial Average index, basing the trading decisions on a neural network that provide reliable results. Other papers on the developed financial markets include [20, 45, 54-58]. Qiu et al. [59] apply the artificial neural network involving a hybrid approach based on the genetic algorithm (GA) and simulated annealing (SA) to improve the prediction accuracy of the ANN of the Japanese Nikkei 225 index and proved it to perform better.

Cao et al. [19] use artificial neural networks to anticipate stock prices for the companies listed on the Shanghai stock exchange and opine neural networks as a useful method to predict prices in emerging markets, such as China. Additionally, Chen and Li [60] compare the five models, namely, the linear AR model, the LSTAR and ESTAR smooth transition autoregressive model, and the two ANN models that are MLP and JCN, and find that neural network technique made more accurate predictions. Additionally, other papers with the Chinese stock market as the sample include [55, 57, 61, 62]. Considering the Asian markets, particularly the Nikkei 225 closing index and Shanghai B-share closing index, Dai et al. [22] develop a time series forecast model by integrating nonlinear, independent component analysis and neural networks and prove a better option for the Asian stock markets.

RQ1: - to consolidate the findings of the existing literature related to the impact of artificial intelligence on stock market predictions

In order to generate optimum investment returns in the real-world stock exchange, many studies have employed decision support systems (DSS) techniques, soft computing models, and hybrid structures. However, Pham et al. [58] propose a hybrid Kansei-SOM model, a recent method using Kansei assessment combined with DSS techniques using collective decision-making for investment in the stock market and show that the proposed method performs better than the other prevailing methods. Another paper by Lin et al. [63] proposes a new technique called empirical mode decomposition combined with the $k$-nearest neighbors (EMD-KNN) method in forecasting the stock index, and the results demonstrate it to be more successful than the other methods. Additionally, the authors in [64] develop a new model combining the EMD with stochastic time strength neural network (STNN) and conclude it as a better model in forecasting stock market fluctuations.

Many researchers and financial analysts focus on nonlinear ties in the movement of the financial market, which calls for a new form of financial analysis, i.e., the nonlinear analysis of integrated financial markets. The study by Poddig and Rehkugler [51] employs artificial neural networks (ANNs) and other econometric models to establish the United States, Japan, and Germany's global reserve, bond, and currency business model. A paper by Cao et al. [19] compares the predictive potential of linear models and multivariate models of the neural networks and suggests neural network as an enhanced and effective method for forecasting stock market movements.

Reviewing the stock market's microstructure from a new perspective, Liang [65] uses the neural network technique to learn the complex linking of stock market information sources and determine that experiments illustrate this association statistically. Alternatively, Li et al. [66] study another theme in the concerned field that is the trading volume and the asset price risk using the sentiment analysis and machine learning approaches, including the ANN and support vector machine (SVM). Another topic of interest is captured by Liang [67] with a focus on studying the relationship between stock news on the Internet and stock price movements using neural network.

RQ2: -to understand the potential of different methodological AI approaches to capture the increased complexity and the complex nature of economic and political relations influencing stock price movements and their volatility

The intense research in neural networks produced new techniques for many potential applications, including the ability to forecast future movements of stocks, indices, and currencies, and additionally, Rehkugler and Poddig [68] conclude that, on comparing its results with those of a traditional model based on the multivariate regression analysis, the neural networks produced relevant results. Many papers sustained the implementation of the ANNs for a long time, even after their inception [69-71].

With the aim to outperform the other individual models, approaches involving the integration or the hybridization of different models in a composite model consisting of numerous linear prediction models, nonlinear models, or variations of both are implemented [46]. Kim et al. [72] investigate the efficiency of a hybrid approach with the timedelay neural networks (TDNNs) and the genetic algorithms (GAs) in identifying time-based stock market predictive tasks and find that evaluating the integrated solution is better than the traditional TDNN and the recurrent neural networks (RNNs). Additionally, to predict the settlement price of stock index futures, Li [30] develops a hybrid model involving the decomposition of empirical mode and function of the radial base that results into higher prediction accuracy. Forecasting future trends are one of the key considerations when using a prediction model. Hence, researchers continue to provide upgradations in the time series models. Since the artificial neural networks need a large amount of data, Khashei et al. [73] propose a modern hybrid neural artificial networks and fuzzy regression model for time series forecasting and conclude it to yield better results.

Bohn et al. [74] discuss the new system named MoneyBee that predicts the stock market values, especially from the German stock market, and conclude this information technology product as an innovation due to its cooperation between multiple high-level program groups. 
The estimation of stock market movements is one of the key fields, with several approaches used, including the conventional computational techniques to artificial neural networks. However, the traditional approach to statistical economics has difficulties scaling because of noise and nonlinearity in time series [75]. Considering this feature of the traditional approach, Zhang et al. [75] propose the simple wave signal decomposition-based prediction model and the introduction of the $\alpha$-counting instantaneous frequency of the simple wave and find it a better model.

Clearly, the literature states that whenever a new hybrid model is implemented, or a new approach is adopted to predict the stock market movements, the results produced are positive and favorable from the investment point of view. Hence, this indicates that every new technique and methodology implemented will lead to consistent improvements in the relevant models in artificial intelligence and, in particular, neural networks.

RQ3: to highlight the future research directions that may create value with AI in the context of stock market predictions

Recent research studies have paved the way for the inclusion of neural networks with AI for forecasting stock markets. Rather et al. [46] suggested the use of AI models for optimal portfolio selection through intelligent modeling. Further, risk modeling and return forecasting can be modelled by using the subfield of $\mathrm{AI}$, which is machine learning (ML) [48]. This may enhance the probability to achieve better optimization models in the prediction of stocks in the longer run.

RQ4: to understand the capacity of AI in predicting the financial market behavior during pandemic times as COVID-19

The present review is an attempt in providing a constructive path for forecasting stock markets, and the use of AI models in predicting the financial market behavior during pandemic times seems promising. The correlation that may arise due to sentiment-related volatility in stock markets [76] may be analysed through the machine learning models.

2.2. Methods. The research approach is influenced by the works in [77-80]. It is important to note that a systematic review involves reading several excerpts from an article, considering not only the overview of the keywords and the abstract but a thorough examination of each paper, taking their methods, conclusions, and findings into consideration. This is imperative to categorize their content more meaningfully while examining a particular field of study. Therefore, this review takes into consideration the research works that directly or indirectly discuss the applications of neural networks and artificial intelligence in predicting stock market by carrying out the following activities:

(1) Analyzing the articles previously published

(2) Providing a short description of the contribution of these articles

(3) Categorizing and coding the different parameters
(4) Describing their different contributions

(5) Providing the scope for future research to fill the gaps identified herein

The authors jointly delineated two keywords, namely, "neural network" and "stock market forecasting." "Fuzzy logic" and "artificial intelligence" were decided as synonymous with "neural network." In contrast, "stock return," "share market," and "share price" were decided to be used as synonymous with the "stock market" for searching the literature. The worldwide accepted online database, Web of Science (WoS), was used for searching the relevant papers. The search was conducted on the Web of Science database on December 24, 2017, using the following BOOLEAN criteria: TS $=(($ Neural Network* OR Fuzzy Logic* OR Artificial Intelligence) AND (stock market* or stock return* or stock price* or share market* or share return* or share price $\left.^{*}\right)$ ).

This resulted in an initial list of 1040 papers, as shown in Figure 1.

The list of 1040 papers is discussed for designing an objective criterion to select/reject the papers for review. Manual exclusion and inclusion are done by the authors as follows.

Each paper was examined individually by the authors as A (accept), B (reject), and C (doubtful), which was carried out solely based on the abstract and the keywords. The results are showcased in Figure 1, which exhibits that 1040 papers were extracted from the database in the first stage, out of which 250 papers were accepted for review, 605 were rejected, and 185 were put in the doubtful category.

The second stage carried out the reassessment of these papers, which involved going through the entire paper for better understanding and correct categorization. 128 papers were rejected based on an irrelevant field of study. Eventually, 57 were accepted from the list of doubtful papers.

Finally, a total of 307 papers were selected for the systematic review. Table 1 highlights the categories and subcategories for the systematic literature review.

\section{Results}

\subsection{Descriptive Results}

3.1.1. Geographical Distribution. The first category deals with the geographical base studied in the existing literature. Table 2 represents the geographical area distribution.

It is evident from Table 2 that the majority of contributions focus on countries from Asia, which is assigned code B. Asia is representative of $39 \%$ of research in artificial neural networks (ANNs) for stock market prediction. Code C, representing the USA, shares $15 \%$ of its research work in this context. CW countries share $13 \%$ of their knowledge base in this background. At the same time, 33\% of geographical distribution does not belong to any particular geographical location. It is important to undertake more research in designing prediction models for stock markets. As stock markets play a major role in a country's economic growth, it is important to have some prediction models which can help 


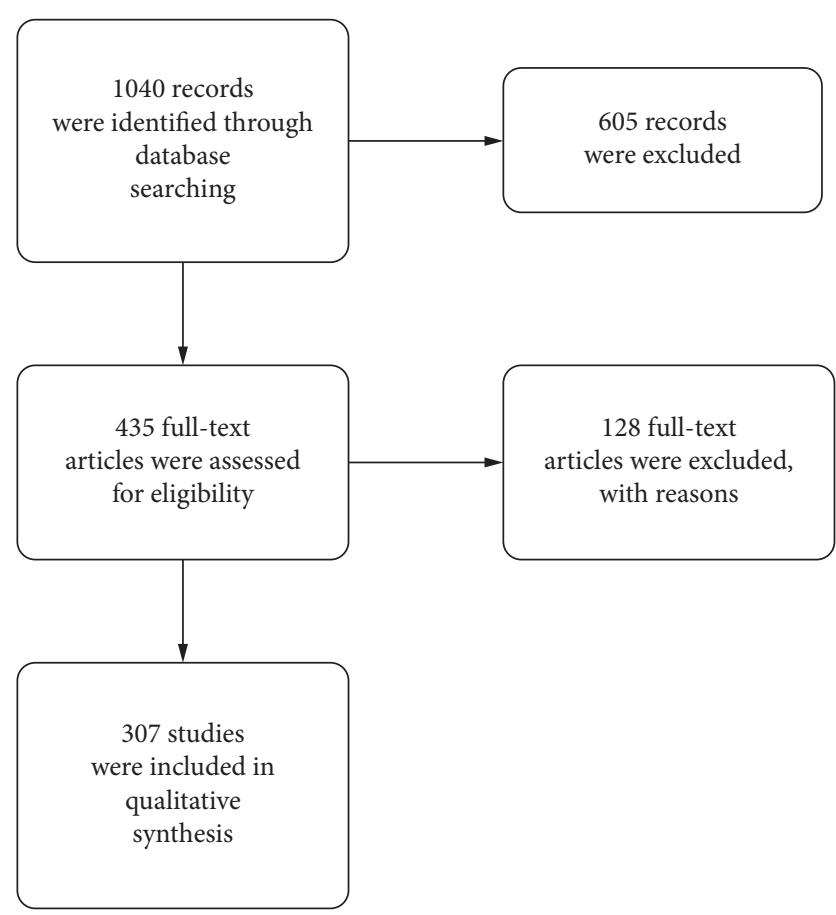

FIgURE 1: Study flow diagram (PRISMA figure).

in the forecasting of price movements in stock markets for the benefit of investors. Figure 2 represents the geographical area distribution.

3.1.2. Context. The second category relates to the coverage and is divided into three categories: A stands for developed countries, B for developing countries, and $\mathrm{C}$ for not applicable. Table 2 depicts that $55 \%$ of the contribution is made by developed countries and $41 \%$ is by developing countries. The majority of studies have taken place in developed countries. This is suggestive of the fact that researchers in developed nations have started analyzing the issue of prediction of stock prices. However, this is a major concern of investors across the globe, and such studies need to be undertaken in developing nations also (Figure 3).

Gap 1: studies focusing on the future of artificial neural networks in stock market prediction models in developing countries must be taken up.

3.1.3. Method. This category of coding indicates the method applied to the available. Table 2 presents the methodology with seven categories.

Category D presents the maximum number of papers. These papers have used more than one method of analysis. Conceptual papers are denoted as code $\mathrm{C}$, which represents the next highest number of studies. Figure 4 presents the methodology from the existing literature.

It can be concluded that conceptual and theoretical work has been done in this context. The gap which emerges is as follows.

Gap 2: there is much wider scope in the field of artificial intelligence to implement other methodological approaches; for instance, conducting a case study or a survey or an experiment using a hybrid model can further help in the development of more generalized models of stock prediction.

3.1.4. Main Subject. The category of the main subject is classified into five types, as mentioned in Table 2 . The maximum number of publications are available in the field of neural network and other computing techniques. The analysis of this category implies that a major part of the literature talks about studies on the combination of artificial intelligence and neural networks [14, 57, 81-83]. Research related to predicting stock indices, such as genetic algorithms and neural networks, and linear and nonlinear models recognizes patterns by estimating coefficients and their statistical significance. However, most agents in the stock market use language that incorporates qualitative aspects such as the price of the asset, but the authors in [52] opine that predictive models of fuzzy logic achieve statistically significant and positive returns when used in trading strategy [84]. Model predictive control (MPC) is regarded as the most widely applied control technique capable of handling constraints and incorporates other economic considerations [85]. In the context of portfolio optimization, where the challenge also lies in finding the optimal trade-off between risk and return over a fixed time horizon, Herzog et al. [86] propose to use the model predictive model (MPC) to optimize the portfolio by the probabilities and parameters of the implied regime including transaction costs, risk aversion, and other restraints. Nystrup et al. [84] employ the model predictive control (MPC) to optimize a portfolio based on forecasts of the mean and variance of financial returns from a hidden Markov model and conclude that MPC yields better returns and relatively lesser risk than investment in other stock markets. On the other hand, Yamada and Primbs [87] employ MPC in the context of the hedge funds incorporating the issues of gross exposure and transaction costs, while Dombrovskii and Obedko [88] adopt MPC to develop feedback portfolio optimization strategies, indicating extensive reliability on this technique in financial applications, especially in cases of portfolio optimization and dynamic hedging. Concerning our main topic, extensive work could be taken up, which will ultimately lead to algorithms and prediction models in this background (Figure 5).

3.1.5. Themes. The themes are divided into ten different categories, as depicted in Table 2. It can be drawn that a major part of the studies available is in the field of computer sciences and business economics (Figure 6).

There arises a need for more studies to be taken up under themes of material sciences, soft computing, optimization techniques, automation, and control system. This brings us to the following gap.

Gap 3: the scope of research lies in the trade-off between different optimization algorithms and the adoption of the best algorithm as the solution. This can be achieved by filling the gaps under other themes of science as they can provide 
TABle 1: Categories and subcategories of the systematic literature review.

\begin{tabular}{|c|c|c|}
\hline Category & Meaning & Codes for alternatives \\
\hline 1 & Geographical distribution & $\begin{array}{c}\text { Commonwealth countries } \\
\text { Asia } \\
\text { USA } \\
\text { Not applicable } \\
\end{array}$ \\
\hline 2 & Context & $\begin{array}{c}\text { Developed countries } \\
\text { Developing/emerging countries } \\
\text { Not applicable }\end{array}$ \\
\hline 3 & Methodology & $\begin{array}{c}\text { Quantitative } \\
\text { Qualitative } \\
\text { Conceptual } \\
\text { Quantitative/qualitative or qualitative/quantitative } \\
\text { Survey } \\
\text { Case study } \\
\text { Not applicable }\end{array}$ \\
\hline 4 & Main subject & $\begin{array}{l}\text { Stock return prediction } \\
\text { Other financial returns prediction } \\
\text { Artificial intelligence } \\
\text { Neural networks } \\
\text { Other computing techniques }\end{array}$ \\
\hline 5 & Themes & $\begin{array}{c}\text { Neuroscience } \\
\text { Optimization techniques (science tech.) } \\
\text { Business economics } \\
\text { Soft computing (engineering) } \\
\text { Material science } \\
\text { Automation and control system } \\
\text { Operational research and management science } \\
\text { Physics and mathematics } \\
\text { Computer science } \\
\text { Other topics }\end{array}$ \\
\hline 6 & Contribution & $\begin{array}{c}\text { New perspectives } \\
\text { Consistent with previous literature } \\
\text { Previous model with different datasets/time periods } \\
\text { Comparative study } \\
\text { Not applicable } \\
\end{array}$ \\
\hline 7 & Analysis period & $\begin{array}{c}\text { Less than } 3 \text { years } \\
\text { Between } 3 \text { and } 5 \text { years } \\
\text { Between } 5 \text { and } 10 \text { years } \\
\text { More than } 10 \text { years } \\
\text { Not applicable }\end{array}$ \\
\hline
\end{tabular}

TABLE 2: Codes and categories of selected papers.

\begin{tabular}{lccccccc}
\hline Code & Geographical distribution & Context & Method & Main subject & Themes & Contribution & Analysis period \\
\hline A & $40(13 \%)$ & $169(55 \%)$ & $3(1 \%)$ & $23(7.49 \%)$ & $6(2 \%)$ & $40(13.02 \%)$ & $25(8.14 \%)$ \\
B & $120(39 \%)$ & $126(41 \%)$ & $9(3 \%)$ & $43(14 \%)$ & $4(1 \%)$ & $34(11.07 \%)$ & $14(4.56 \%)$ \\
C & $46(15 \%)$ & $12(4 \%)$ & $52(17 \%)$ & $24(7.87 \%)$ & $54(18 \%)$ & $35(11.40 \%)$ & $124(40.39 \%)$ \\
D & $101(33 \%)$ & NA & $126(41 \%)$ & $51(16.61 \%)$ & $15(5 \%)$ & $45(14.65 \%)$ & $144(46.90 \%)$ \\
E & NA & NA & $31(10 \%)$ & $52(16.93 \%)$ & $2(1 \%)$ & $43(14.33 \%)$ & NA \\
F & NA & NA & $37(12 \%)$ & NA & $4(1 \%)$ & NA & NA \\
G & NA & NA & $49(16 \%)$ & NA & $4(1 \%)$ & NA & NA \\
H & NA & NA & NA & NA & $19(6 \%)$ & NA \\
I & NA & NA & NA & NA & $192(63 \%)$ & NA & NA \\
J & NA & NA & NA & NA & $7(2 \%)$ & NA \\
Multiple & NA & NA & NA & $114(37.13 \%)$ & NA & $109(35.50 \%)$ & NA \\
\hline
\end{tabular}




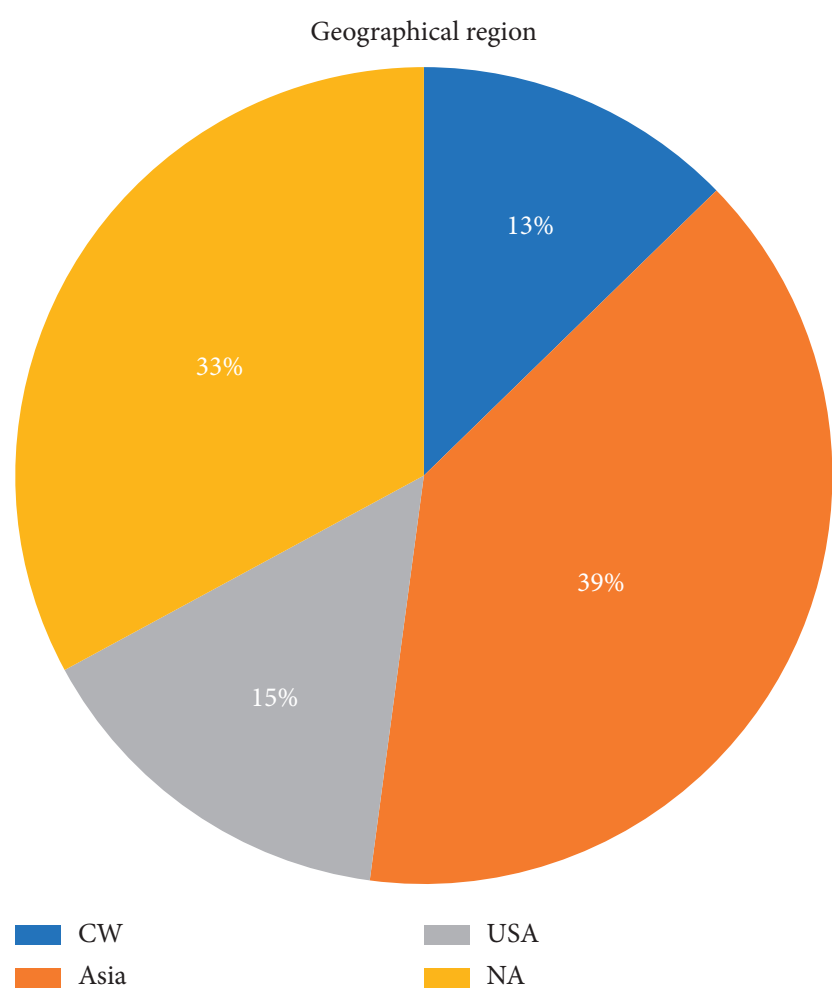

Figure 2: Distribution of the geographic region in the existing literature.

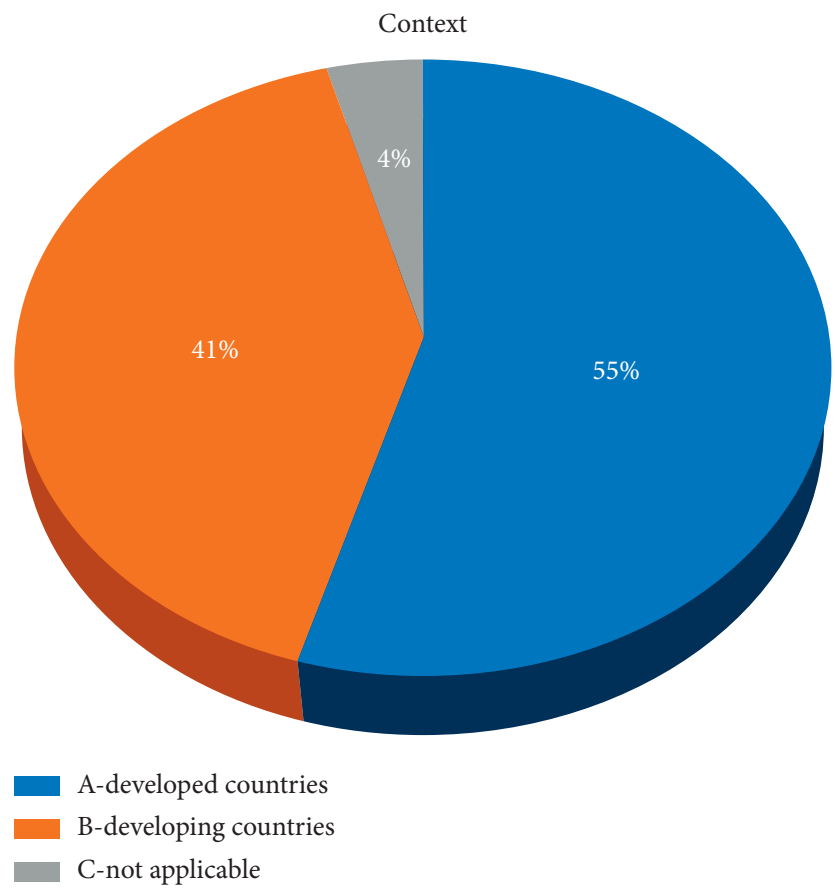

Figure 3: Context of existing research papers.

better insights into AI for the development of stock market prediction models.

3.1.6. Contribution. This classification presents the contribution of the articles understudy, presented in Table 2. The contribution made by category $\mathrm{D}$ is the maximum number

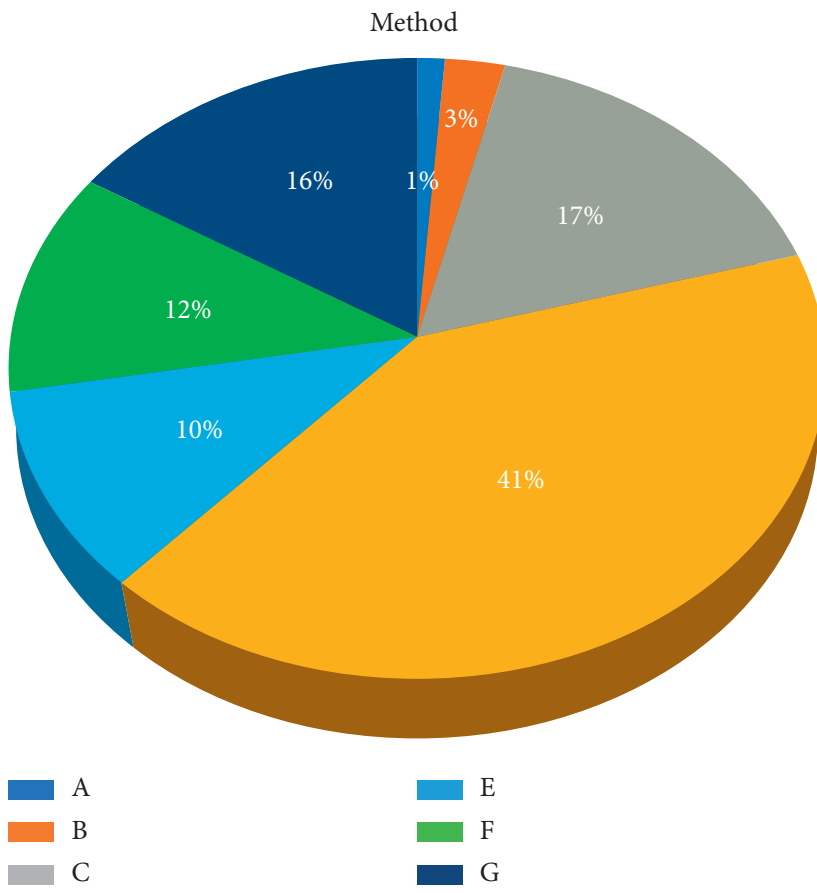

FIgURE 4: Methodology employed in previous papers.

of 45 papers followed by category "E" with 44 and further followed by "A" with 40 . Hence, it seems to be an ideal spread of the previous literature with a fine number of papers concentrating on either implementing previously developed models with a new dataset or drawing a comparison between different techniques or an extension of findings from the previous literature (Figure 7).

3.1.7. Analysis Period. The analysis period indicates that, in the last three years, only 25 papers are published. It is also less for a period of 3 to 5 years, accounting for only 14 papers. However, AI as a concept emerged long back in the 1960 s and the concept of the neural network is indeed an old established concept in neurology. The merging of these two concepts is still in a quandary. There is a dire need to uptake more work in this field and reap benefits out of AI and neural networks for the prediction of stock markets (Figure 8).

Gap 4: more studies are required to see the consistency throughout the time period since the inception of these three topics, viz., AI, neural networks, and stock market forecasting.

\section{Discussion}

Using the method suggested in [77-80], an analysis of the relevant literature available on the Web of Sciences (WoS) was conducted to identify the major themes in studying the application of artificial intelligence and related techniques in predicting stock behavior. The methodological details are presented in Section 2 of this paper. The characteristics and parameters studied by the existing literature are segregated and presented in this section. 
Main subject

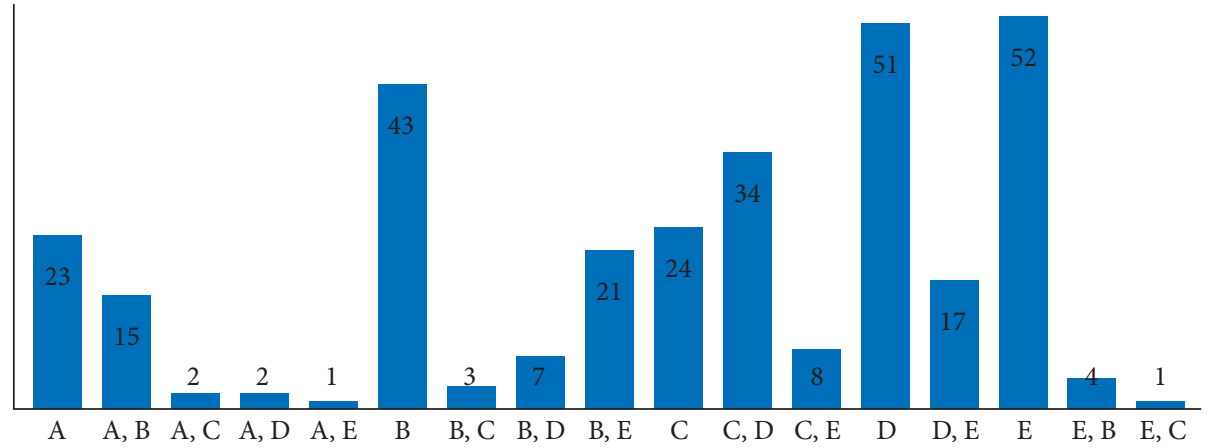

FIgURE 5: Distribution of main subject in the existing literature.

Themes

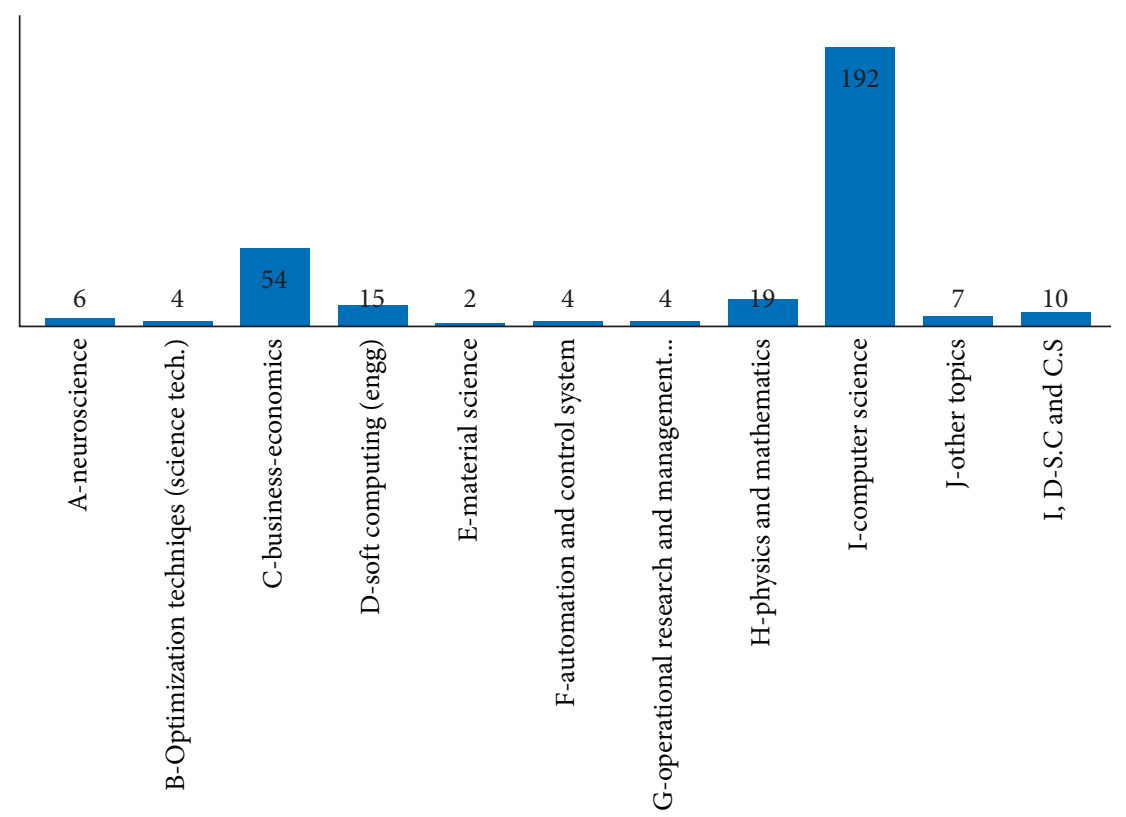

Figure 6: Themes of papers.

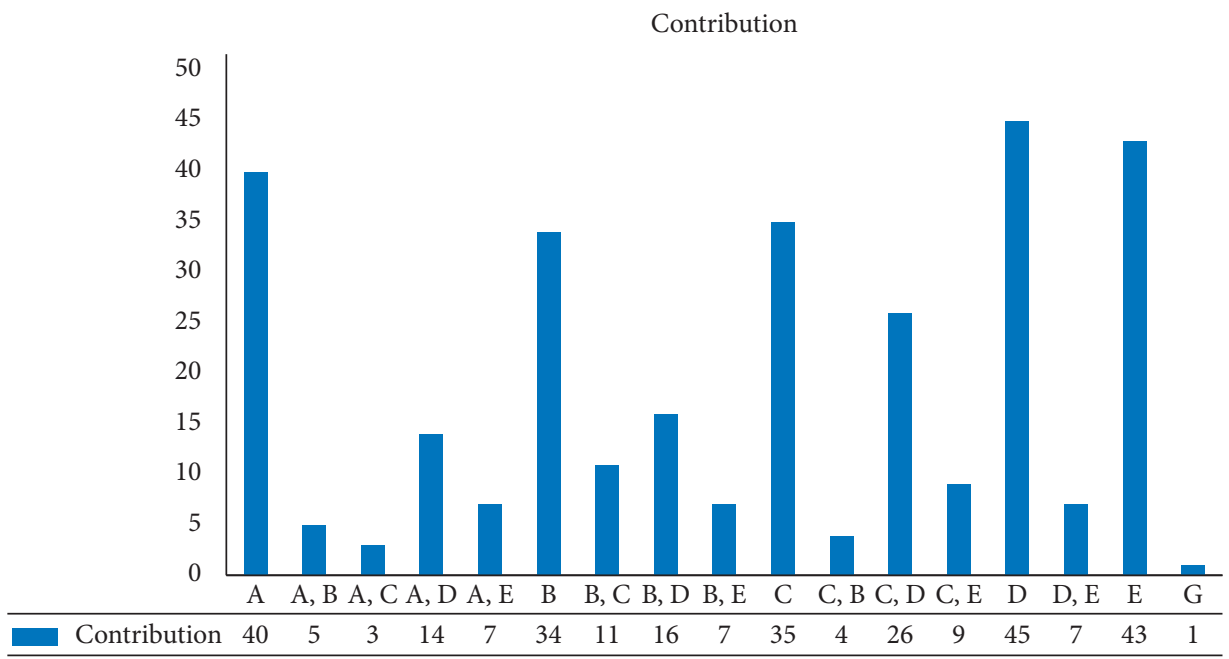

FIgURE 7: Histogram showing the contribution to the paper. 
Analysis period

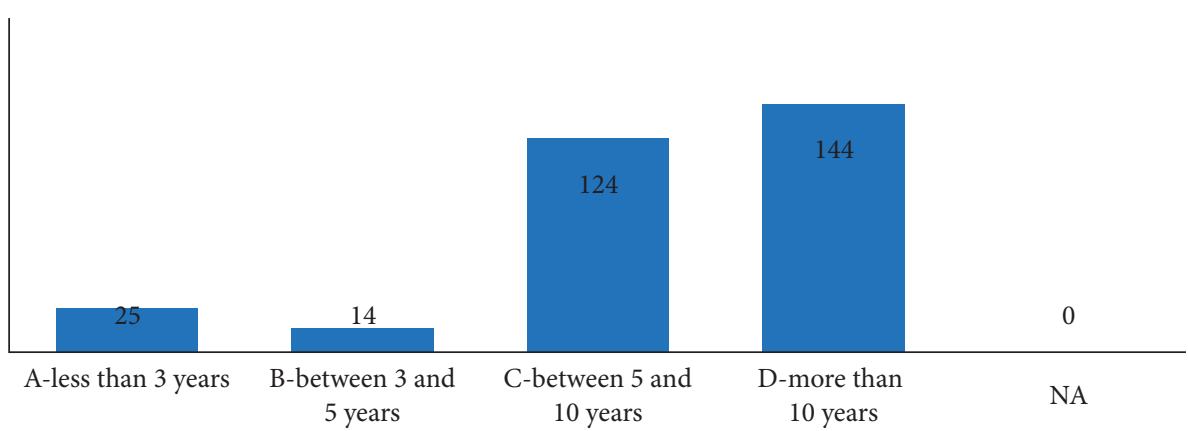

FIGURE 8: Analysis period from the existing literature.

4.1. Soft Computing. In the financial world, soft computing is gathering traction. A variety of real and potential soft computing technologies are employed in the financial sector, including commodity and retail market estimates, trade, portfolio management, credit scoring, or projections of financial distress [89]. Soft computing includes a variety of techniques that replicate the ability of the human imagination that applies reasoning approaches that are subjective and not precise. The term "soft computing" was coined by Zadeh in the early nineties [90], concluding fuzzy logic, neural network theory, and probabilistic reasoning as the main components of soft computing. Securities and foreign exchange forecasting is one classical field of soft computation in which forecasts of the conduct of hybrid currencies, currency exchange rates, and stock prices are determined [89]. A significant example of soft computation techniques used in stock market forecasting is given byBoyacioglu and Avci [11], where the authors utilize an adaptive networkbased fuzzy inference system, with which they have a prediction accuracy of $98.3 \%$ for the Istanbul Stock Exchange. The authors use a combination of macroeconomic variables and indices with a set of if-then rules and layers based on the principles of ANN and fuzzy logic. Current research on predictive models in financial economics and econometrics distinguishes between parametric models and nonparametric models. In the case of option pricing models, the famous Black-Scholes model is an important primer for parametric models estimating option prices.

On the other hand, methods such as extreme learning machines and support vector regressions are mainly nonparametric models, with which financial predictions can be done. Das and Padhy [91] suggest a combination of parametric and nonparametric methods mentioned here in order to increase the predictive power of option pricing models. Here, the hybrid mode superiority is due to return distributions being nonnormal and the need for adaptive learning, which arises from the extreme learning machines method.

4.2. Neural Networks. As a branch of computational science, the neural network encompasses a broad range of techniques of function modeling focused on interconnected processing components, known as neurons, which work together to generate a particular output. Among the important approaches are the multilayer perceptrons, radial basis networks, or self-organizing maps [89]. Jayne et al. [92] investigate the applicability of neural networks by forecasting the values of each share, taking into account the general index value, and state that neural networks learn the complex mapping between ideal attributes and the particular domain parameters. Results from the multilayer perceptron method (MPL) and radial basis function (RBF) tests are good and acceptable considering the type of inversion problem addressed. Corresponding to this, Kim and Lee [93] compare the genetic algorithm (GA) with the linear transformational model (LTM) and fuzzy transformational model (FTM) for the artificial neural networks to function better in predicting the stock market patterns and report reduction in the irrelevant factors for stock market prediction. On the other hand, stock opening price forecasting has also gained momentum in recent years. To improve the accuracy of this forecasting, Qun et al. [94] propose a model incorporating the emotional data along with the actual behavior data and report improvement in the prediction accuracy. Accordingly, Nayak et al. [95] study the neural network of artificial chemical reaction to prepare multilayer perceptrons for stock market index forecasting and conclude significant improvement in the prediction accuracy. It cannot be concluded that neural networks always outperform traditional models in financial markets, as pointed out by Bahrammirzaee [96], who finds out that the opposite can also be true. Nevertheless, the use and performance of NNs are encouraging due to their numeric nature, their distributionfree approach, and the ability of NNs to update data. Nevertheless, due to some limitations in technical aspects of $\mathrm{NN}, \mathrm{NN}$ itself can sometimes be problematic to use-in that case, hybrid models combining $\mathrm{NN}$ approaches with other techniques can be used [96]. One example of such hybridization of NN will be mentioned in Section 4.4.

4.3. Artificial Intelligence. AI is viewed as an alternative to predictive modeling. This computer science, or systems engineering, field was originally introduced in the 1950s to develop machinery intelligence [54]. Since then, a variety of AI methods have developed, including the Bayesian networks, artificial neural networks (ANNs), expert systems, support vector machines, and fuzzy-logic-based techniques. 
In comparison with statistical techniques, AI does not make the same data assumptions as regression analysis. It performs well within datasets contaminated by variable noise and is effective in the impartial and semicontrolled analysis of data [54]. However, many real financial applications have uncertain behavior that changes over time, and this problem causes an increased interest in artificial intelligence applicability. Bahrammirzaee [96] reviews three AI techniques, namely, artificial neural networks, expert systems, and hybrid intelligence systems in the financial market and proves the AI techniques are superior to the traditional statistical methods in terms of their accuracy, majorly regarding the nonlinear patterns.

Alternatively, Li et al. [97] propose a modern blend prediction model based on AI techniques and integrated forecast concept, which may direct the investor's businesses in the real stock market and prove to be an effective instrument for decision making investments. Additionally, the authors in $[59,98]$ apply the ANN and genetic algorithm (GA) and find that this hybrid approach improves the stock prediction accuracy significantly and outperforms the traditional backpropagation (BP) learning algorithm. Wu and Duan [83] compare network structures of different neural networks in predicting the price trend of the Chinese stock market and conclude that the dynamic relationship between investors and market volatility can be thoroughly illustrated. Bebarta et al. [99] propose a model that selects optimum nonlinear combinations of Indian stock forecasting. The model proposed by the authors makes use of an evolutionary algorithm to optimize the weight parameters of different functional expansions to improve forecast accuracy.

Management of stock portfolios is a challenging task, and to solve such problems, artificial intelligence models are applied, where Rather et al. [46] conduct a survey highlighting the traditional mathematical models to artificial intelligence-based models available in recent articles. One problem that they identify is that, in many cases, linear and mathematical models for portfolio optimization work fairly well so that there may be no need for AI models. In addition to that, one common limitation of these AI models is the slow convergence and the fact that there is no guarantee for an optimal solution. One example of an unsuccessful attempt to make use of ANN in combination with genetic algorithms is given in [98], where even the improved version of their earlier model has a prediction accuracy of $63 \%$. This also indicates that the complex nature of ANN cannot immediately deliver efficient and concrete predictions even though some scholars found methods to fasten the learning process (see, e.g., [12]).

Nevertheless, the evolutionary computation can deliver evidence from another perspective than optimization, which is known for being a primer in ergodic economic theory, as recently pointed out by Menger-Anderson [100]. Ghandar et al. [101] show that, using evolutionary computing methods, the machine itself can develop evolutionary trading rules with which an excellent performance in everevolving market conditions can be reached. On the other hand, Hamed et al. [12] combine ANN and MLP approaches with a method from signal processing called blind source separation technique. The signal processing technique utilized by the authors not only optimizes the learning process of the neural network but also fastens this process. Through this improvement, accurate and efficient results have been obtained for Microsoft stock movements, among others.

4.4. Fuzzy Logic. After being considered one of the main components of soft computing, fuzzy logic is derived from fuzzy set theory dealing with theoretical reasoning rather than precisely derived rationale. Unlike the traditional logic, it arrives at conclusions based on vague, ambiguous, noisy, or incomplete information [89]. Employing a fuzzy logicbased approach simplifies the design problem and describes the ambiguity and vagueness of pattern functions. It includes uncertainty in the trading decision system that advises the investor on how much and where to invest. Naranjo et al. [102] illustrate this methodology by proposing a fuzzy trading system that reveals improvement in pattern recognition and provides more benefits in a less volatile fashion than most trading structures. However, previous literature finds certain drawbacks in the forecasting models. To refine these, Wei et al. [103] propose a hybrid model employing a fuzzy inference system (FIS) and argue that the model is superior to the previous traditional models due to improvement in the forecasts generated. Since neural networks can be considered as having a black box nature sometimes [104], the problem is that these cannot be used to determine a causality relation between dependent and independent variables. To overcome this problem, instead of rejecting neural networks completely [104], make use of a hybridization technique to generate a fuzzy neural network model. This model combines the reasoning style from fuzzy models and learning styles of neural networks to yield interpretable results and high profits for stock trading decisions. Through this hybrid model, the authors show an improvement of neural network-based decision rules for stock trading. Alternatively, Bekiros et al. [105] propose a volatility-based neuro-fuzzy model to predict FTSE100 and New York Stock Exchange returns. This contribution shows that considering volatility changes in a neuro-fuzzy model can improve the accuracy of stock market forecasts and it outperforms other approaches such as a Markov switching model, a feedforward neural network model, and a buy and hold strategy when transaction costs are also taken into account. The managerial implication of this model is that a neuro-fuzzy model incorporating volatility changes can bring higher returns than the approach for passive fund management.

4.5. Stock Returns. The economic and social well-being of developing countries with reasonably privatized economies depends heavily on the financial sector in a region, which is seen as an important factor for growth and development. Over the years, researchers are trying to promote financing by offering credit and other financial goods, predict market patterns, model market, and consumer conduct, manage the portfolio, open stock price allocation, predict defaults and bankruptcy, etc. In respect of these, several methods are used that can be classified as parametric (e.g., logistic regression 
and discriminatory analysis), nonparametric (e.g., decision trees) mathematical techniques, and soft computing (e.g., artificial intelligence algorithms) techniques [96].

Investors, industrialists, and researchers remained focused on stock estimation and investment in suitable stocks. In the years, several models and techniques of artificial intelligence have been developed to solve such problems. However, Box and Jenkins's ARIMA models have gained popularity in the time series prediction field, while linear prediction models are still used in practice [106]. Complementary to this, Rather et al. [46] survey articles on stock prediction and stock selection for portfolios and opine more precise demand forecasts by AI-based models. Karathanasopoulos [107] introduces a new short-term adaptive model, i.e., partial swarm optimizer combined with linear and nonlinear models to forecast the daily closing returns of FTSE100 exchange-traded funds (ETFs) and find the model to perform well in terms of correct directional change.

On the other hand, Li et al. [108] forecast the REITs and stock indices by Group Method of Data Handling (GMDH) neural network method with Hurst and confirm the model to perform better than the conventional forecasting algorithms, including ARIMA, the single and double exponential smooth, and the neural network backpropagation. Additionally, a paper by Zhong and Enke [109] present a systematic data mining method using artificial neural networks and logistic regression models, to predict the S\&P 500 Index ETF (SPY) daily return, and conclude that the risk-adjusted returns of the trading strategies are higher than the comparable benchmark. Bildirici and Ersin [10] focus on an M-GARCH type model that makes use of ANNs to improve forecasting accuracy. The novelty of this model in comparison with similar GARCH models is the increased predictive power of the model involving the regime-switching structure augmented with neural networks. The approach proposed by Chang et al. [110] makes use of the simplest form of business cycle theory, namely, the theory that tells us that there are ups and downs which we call turning points regarding stock prices, but also the economy in general. The novelty of the approach is to decompose historical data into segments, through which the authors identify temporary turning points by using piecewise linear representation. The model therefore gives investors clues about buying, selling, or holding stocks, which is a more preferred approach than forecasting the stock price only.

Additionally, the model predictive control (MPC) technique is developed by Herzog et al. [86] to solve restricted stochastic problems in terms of portfolio optimization, including inherent nonlinearity, constraints, and uncertainty [111]. Dombrovskii and Obedko [88] consider optimum portfolio selection issues subject to investment, trade, and various borrowing and lending rates limitations, use MPC for designing optimization feedback portfolio strategies, and further test the approach on real data of the Russian Stock Exchange, Moscow Interbank Currency Exchange, and New York Stock Exchange. Conversely, to gain insights into the stock market and allocation of capital, Trimborn et al. [112] employ MPC to approximate and solve the optimization of the utility function. To predict shifts in the term interest rate structure, Zantedeschi et al. [113] propose a dynamic product partition model (PPM) that relates macrovariables to term structures and indicate major economic disruptions, including recessions.

4.6. AI and Knowledge Management. Artificial intelligence and knowledge management developed historically from different roots, but they share a common ground due to the subjective, tacit, dispersed nature of knowledge [114]. Sanzogni et al. [114] propose that collective tacit knowledge available in society and transferred to an individual via his or her interactions with the society, tacit relational knowledge based on contingencies concerning human interactions, and tacit somatic understanding lying within the mind of an individual are building the common grounds for these two concepts. The authors point out the fact that AI can be used to support human-driven knowledge processes, which are necessarily subjective. Still, the state-of-the-art research and practices show that AI is leading the way to autonomous intelligent machines which will rather substitute humandriven knowledge processes. The authors note that AI and $\mathrm{KM}$ evolved in parallel ways but need to be integrated for further research since AI-based technologies can be a key to the implementation of new knowledge strategies and KM visions for decision-making.

Furthermore, it is also noticed by the authors that AI technologies may be unaware of their actions and the political consequences of these actions, and this challenge can be managed by KM strategies. The latter point seems to be especially relevant for financial markets since disseminating fake or real news has a significant effect on these. In contrast, these build the macroeconomic implications of $\mathrm{AI}$ and its complex relationship with KM. Some microeconomic implications can be relevant for individual behavior, especially regarding individuals who directly or indirectly influence stock market prices. A primer in the interaction of these fields had been written by Dong and Zhou [115]. Using ANNs as their point of departure, the authors deliver empirical evidence showing the relation between stock price response and firm size, which differs across different firms. The novelty of this approach is to show that using the whole dividend event data to conclude may lack this differentiation across different types of firms. Hence, managing knowledge on stock price response can be improved by managing knowledge on firm types.

Big data, as an emerging field of application of AI, can be useful for personal knowledge management, as stated by Liu et al. [116]. The authors consider the fields where big data can be useful, such as time management, machine performance monitoring, activity monitoring of mobile devices, healthcare, and web navigation. Concerning financial decision-making, these areas can be improved both for security and for more efficient investment decisions. Nevertheless, this is a challenging issue, since real-world phenomena can be very complex, and often, there can be some omitted variables which may result in false causalities and conclusions [117]. 
TABLE 3: Research gaps and future agenda.

\begin{tabular}{llc}
\hline Gaps & \multicolumn{1}{c}{ Questions } & Related studies \\
\hline $\begin{array}{l}\text { Gap 1-; there is a need to focus on } \\
\text { the future of artificial neural }\end{array}$ & $\begin{array}{c}\text { RQ1: to integrate the findings of the } \\
\text { previous research in the field of } \\
\text { artificial intelligence in stock market } \\
\text { networks in stock market prediction } \\
\text { models in developing countries }\end{array}$ & $\begin{array}{c}\text { of the world, with more focus on the } \\
\text { developing economies }\end{array}$ \\
\hline
\end{tabular}

Gap 2: there is a much wider scope in the field of artificial intelligence to implement other methodological approaches; for instance, $\quad$ RQ2: to adopt other methodological conducting a case study or a survey approaches involving a case study, or an experiment using a hybrid model can further help in the development of more generalized models of stock prediction

Experiments: [11, 29, 75, 91, 97] Survey: $[96,114]$

Case study: [91, 132-136]
RQ3: to conduct more research using a combination of other themes for stock market prediction, also Gap 3: the scope of research lies in because the existing artificial neural choosing the optimal algorithm as the solution. A combination of other themes may provide better insights and models for stock market prediction. networks have not been able to provide effective results [137] and this calls for more advanced techniques such as neuro-fuzzy methods, genetic algorithm, option pricing models, machine learning techniques, and component analysis models
Neuro-fuzzy systems: [104, 105, 138-141]

Genetic algorithm and linear representation methods: [28, 93, 142-148]

Linear regression models: [21, 116, 122, 149]

Option pricing model, machine learning techniques and hybrid combinations with neural networks: [34, 91, 150-153] Component analysis model: [22, 46, 62, 137, 154]

RQ4: the majority of the study is concentrated on longer periods. the time period since the inception Very few studies have conducted an of these three topics, viz., AI, neural experiment or a case study on the networks, and stock market trading prices spread over the forecasting previous 6 months or less

\section{Conclusions}

The paper discussed the relevance of artificial neural networks (ANNs) in stock market prediction to cope up with the challenge of low financial well-being during the crisis of COVID-19. The existing literature in the field relates that AI and neural networks have a promising future together though the extent to which it can be applied should not be neglected. AI can provide multiple algorithms in solving the problems. The combination of neural networks with AI can provide for the development of human neurons and the functioning of the same in the human body. ANNs can help analyze nonlinear problems and more generalization of the solutions provided through this combined approach. Thus, stock prediction tools can be developed through the use of ANNs.

The existing literature on this subject has largely used the conceptual methodology, though a combination of quantitative and qualitative approaches has also been employed in some cases. The theory generalization aspect has not been studied extensively by the literature. It can also be seen that developing countries are not doing so well when confronted with the development of stock prediction models than their counterparts. Witnessing the current era of scientific developments brings us to a state where AI can play a major role in developing models of stock market prediction, and more research studies are needed. The gap formed through this article is the use of a combination of AI as a subject with the neural network as another area and stock market forecasting as another theme, and it will pave the way for future research works. The analyses help highlight four important gaps in the existing literature on the subject.

We focused on the 4 research questions, as outlined in Section 2, and found four important gaps in the existing literature. From these gaps, we formulate the future research agenda to serve as a guideline for future researchers interested in these topics (Table 3).

The limitations of this study can provide a precursor for further studies. The papers have been analysed from the Web of Science only. Other databases can also be referred for addressing new gaps. This study acknowledges the relationship between AI, neural networks, and stock market prediction. Therefore, their use in predicting sentimentrelated volatility in stock markets especially during pandemic times of COVID-19 needs attention. Hence, new perspectives can be brought to light through the use of other databases and running more ML models for forecasting 
during COVID-19. The exploration of newer ideas will result in more application-based studies.

\section{Disclosure}

The funders had no role in the study; in the collection, analyses, or interpretation of data; in the writing of the manuscript; or in the decision to publish the results.

\section{Conflicts of Interest}

The authors declare no conflicts of interest.

\section{Authors' Contributions}

G. D. S. and B. E. conceptualized the study; G. D. S. and M. M. were responsible for methodology; G. D. S., B. E., M. M., M. S., and M. J. performed formal analysis; R. S. U. and T. K. investigated the study; S. S. was responsible for resources; G. D. S., B. E., M. J., T. K., M. M., M. S., R. S. U., and S. S. prepared the original draft; M. S., M. J., and B. E. reviewed and edited the manuscript; $M$. M. visualized the study; R. S. U. supervised the study; G. D. S. was involved in project administration; B. E. was responsible for funding acquisition. All authors have read and agreed to the published version of the manuscript.

\section{Acknowledgments}

The authors wish to thank Bettina Beer from the Graduiertenakademie of TU Dresden for issues associated with project management. This paper has been written as a result of the project IPID4ALL-2017_76 as a collaboration between TU Dresden, GGS Indraprastha University, and All India Institute of Medical Sciences (AIIMS), New Delhi, supported by DAAD and DFG. The authors are thankful to DAAD and DFG for support. Also, Burak Erkut is thankful to Deutsche Bundesbank, which sponsored his second research visit at GGS Indraprastha University and AIIMS.

\section{References}

[1] G. D. Sharma and M. Mahendru, "Lives or livelihood: insights from locked-down India due to Covid-19," Social Sciences \& Humanities Open, vol. 2, no. 1, Article ID 100036, 2020.

[2] G. D. Sharma, A. S. Ghura, M. Mahendru, B. Erkut, T. Kaur, and D. Bedi, "Panic during Covid-19 pandemic! A qualitative investigation into the psychosocial experiences of a sample of Indian people," Frontiers in Psychology, 2020.

[3] G. D. Sharma, G. Talan, and M. Jain, "Policy response to the economic challenge from Covid-19 in India: a qualitative enquiry," Journal of Public Affairs, pp. 1-16, 2020.

[4] G. D. Sharma, G. Talan, M. Srivastava, A. Yadav, and R. Chopra, "A qualitative enquiry into strategic and operational responses to Covid-19 challenges in South Asia," Journal of Public Affairs, Article ID e2195, 2020.

[5] J. G. Júnior, J. P. de Sales, M. M. Moreira, W. R. Pinheiro, C. K. T. Lima, and M. L. R. Neto, "A crisis within the crisis: the mental health situation of refugees in the world during the 2019 coronavirus (2019-nCoV) outbreak," Psychiatry Research, vol. 288, 2020.
[6] The Lancet, "Avoiding panic in a pandemic," The Lancet, vol. 373, no. 9681, p. 2084, 2009.

[7] World Health Organization, Mental Health and Psychosocial Considerations during COVID-19 Outbreak, pp. 1-6, World Health Organization, Geneva, Switzerland, 2020.

[8] B. Erkut, T. Kaya, M. Lehmann-Waffenschmidt et al., "A fresh look on financial decision-making from the plasticity perspective," International Journal of Ethics and Systems, vol. 34, no. 4, pp. 426-441, 2018.

[9] M. Göçken, M. Özçalıcı, A. Boru, and A. T. Dosdoğru, "Integrating metaheuristics and artificial neural networks for improved stock price prediction," Expert Systems with Applications, vol. 44, pp. 320-331, 2016.

[10] M. Bildirici and O. Ersin, "Modeling Markov switching ARMA-GARCH neural networks models and an application to forecasting stock returns," Scientific World Journal, 2014.

[11] M. A. Boyacioglu and D. Avci, "An adaptive network-based fuzzy inference system (ANFIS) for the prediction of stock market return: the case of the Istanbul stock exchange," Expert Systems with Applications, vol. 37, no. 12, pp. 79087912, 2010.

[12] I. M. Hamed, A. S. Hussein, and M. F. Tolba, "An intelligent model for stock market prediction," International Journal of Computational Intelligence Systems, vol. 5, no. 4, pp. 639$652,2012$.

[13] G. Ruxanda and L. M. Badea, "Configuring artificial neural networks for stock market predictions," Technological and Economic Development of Economy, vol. 20, no. 1, pp. 116132, 2014.

[14] Z. Yudong and W. Lenan, "Stock market prediction of S\&P 500 via combination of improved BCO approach and BP neural network," Expert Systems with Applications, vol. 36, no. 5, pp. 8849-8854, 2009.

[15] P. P. Bonissone, "Soft computing: the convergence of emerging reasoning technologies," Soft Computing - A Fusion of Foundations, Methodologies and Applications, vol. 1, no. 1, pp. 6-18, 1997.

[16] O. Akbilgic, H. Bozdogan, and M. E. Balaban, "A novel Hybrid RBF neural networks model as a forecaster," Statistics and Computing, vol. 24, no. 3, pp. 365-375, 2014.

[17] A. Arango and J. D. Velasquez, "Forecasting the Colombian exchange market index (IGBC) using neural networks," IEEE Latin America Transactions, vol. 12, no. 4, pp. 718-724, 2014.

[18] G. Armano, A. Murru, and F. Roli, "Stock market prediction by a mixture of genetic-neural experts," International Journal of Pattern Recognition and Artificial Intelligence, vol. 16, no. 05, pp. 501-526, 2002.

[19] Q. Cao, K. B. Leggio, and M. J. Schniederjans, "A comparison between Fama and French's model and artificial neural networks in predicting the Chinese stock market," Computers \& Operations Research, vol. 32, no. 10, pp. 2499-2512, 2005.

[20] S. Chakravarty and P. K. Dash, "A PSO based integrated functional link net and interval type-2 fuzzy logic system for predicting stock market indices," Applied Soft Computing, vol. 12, no. 2, pp. 931-941, 2012.

[21] J. F. Chang, L. Y. Wei, and C. H. Cheng, "Anfis-based adaptive expectation model for forecasting stock index," International Journal of Innovative Computing Information and Control, vol. 5, no. 7, pp. 1949-1958, 2009.

[22] W. Dai, J.-Y. Wu, and C.-J. Lu, "Combining nonlinear independent component analysis and neural network for the prediction of Asian stock market indexes," Expert Systems with Applications, vol. 39, no. 4, pp. 4444-4452, 2012. 
[23] Á. Dávila, N. Sanchez-Choez, and J. L. Román-Vásquez, "Pronóstico del índice bursátil ecuatoriano (ecuindex) mediante redes neuronales autorregresivas," 3C Empresa :Investigación y Pensamiento Crítico, vol. 6, no. 3, pp. 16-32, 2017.

[24] W.-Q. Duan and H. E. Stanley, "Cross-correlation and the predictability of financial return series," Physica A: Statistical Mechanics and Its Applications, vol. 390, no. 2, pp. 290-296, 2011.

[25] K. E. Fish, J. D. Johnson, R. E. Dorsey, and J. G. Blodgett, "Using an artificial neural network trained with a genetic algorithm to model brand share," Journal of Business Research, vol. 57, no. 1, pp. 79-85, 2004.

[26] V. Georgescu, "Robustly forecasting the bucharest stock exchange bet index through a novel computational intelligence approach," Economic Computation and Economic Cybernetics Studies and Research, vol. 44, no. 3, pp. 23-42, 2010.

[27] C. M. Hsu, "A hybrid procedure for stock price prediction by integrating self-organizing map and genetic programming," Expert Systems with Applications, vol. 38, no. 11, pp. 14026-14036, 2011.

[28] H.-j. Kim and K.-s. Shin, "A hybrid approach based on neural networks and genetic algorithms for detecting temporal patterns in stock markets," Applied Soft Computing, vol. 7, no. 2, pp. 569-576, 2007.

[29] K.-j. Kim and H. Ahn, "Simultaneous optimization of artificial neural networks for financial forecasting," Applied Intelligence, vol. 36, no. 4, pp. 887-898, 2012.

[30] H. F. Li, "Price forecasting of stock index futures based on a new hybrid EMD-RBF neural network model," Agro Food Industry Hi-Tech, vol. 28, no. 1, pp. 1744-1747, 2017.

[31] C.-J. Lu, "Integrating independent component analysisbased denoising scheme with neural network for stock price prediction," Expert Systems with Applications, vol. 37, no. 10, pp. 7056-7064, 2010.

[32] D. Ormoneit, "A regularization approach to continuous learning with an application to financial derivatives pricing," Neural Networks, vol. 12, no. 10, pp. 1405-1412, 1999.

[33] A. Parisi, F. Parisi, and J. L. Guerrero, "Neural network models for forecasting stock market indices," Trimestre Economico, vol. 70, no. 280, pp. 721-744, 2003.

[34] S. Pyo, J. Lee, M. Cha, and H. Jang, "Predictability of machine learning techniques to forecast the trends of market index prices: hypothesis testing for the Korean stock markets," PLoS One, vol. 12, no. 11, 2017.

[35] C. O. Ribeiro and S. M. Oliveira, "A hybrid commodity priceforecasting model applied to the sugar-alcohol sector," Australian Journal of Agricultural and Resource Economics, vol. 55, no. 2, pp. 180-198, 2011.

[36] S. Safi and A. White, "Short and long-term forecasting using artificial neural networks for stock prices in Palestine: a comparative study," Electronic Journal of Applied Statistical Analysis, vol. 10, no. 1, pp. 14-28, 2017.

[37] C.-H. Su, T.-L. Chen, C.-H. Cheng, and Y.-C. Chen, "Forecasting the stock market with linguistic rules generated from the minimize entropy principle and the cumulative probability distribution approaches," Entropy, vol. 12, no. 12, pp. 2397-2417, 2010.

[38] A. Tan, C. Quek, and K. C. Yow, "Maximizing winning trades using a novel RSPOP fuzzy neural network intelligent stock trading system," Applied Intelligence, vol. 29, no. 2, pp. 116-128, 2008.
[39] J. L. Ticknor, “A Bayesian regularized artificial neural network for stock market forecasting," Expert Systems with Applications, vol. 40, no. 14, pp. 5501-5506, 2013.

[40] C.-F. Tsai and Y.-J. Chiou, "Earnings management prediction: a pilot study of combining neural networks and decision trees," Expert Systems with Applications, vol. 36, no. 3, pp. 7183-7191, 2009.

[41] X. D. Wu, M. Fung, and A. Flitman, "Forecasting stock market performance using hybrid intelligent system," in Computational Science -- Iccs 200, Proceedings Pt 2, vol. 2074, pp. 447-456, Springer-Verlag Berlin, Berlin, Germany, 2001.

[42] S. X. Xu and M. Zhang, "An adaptive activation function for higher order neural networks," in Al 2002: Advances in Artificial Intelligence, vol. 2557, pp. 356-362, Springer-Verlag Berlin, Berlin, Germany, 2002.

[43] C.-H. Yeh and C.-Y. Yang, "Examining the effectiveness of price limits in an artificial stock market," Journal of Economic Dynamics and Control, vol. 34, no. 10, pp. 2089-2108, 2010.

[44] J. Yim, "A comparison of neural networks with time series models for forecasting returns on a stock market index," in Developments in Applied Artificail Intelligence, Proceedings, vol. 2358, pp. 25-35, Springer-Verlag Berlin, Berlin, Germany, 2002.

[45] X. Zhu, H. Wang, L. Xu, and H. Li, "Predicting stock index increments by neural networks: the role of trading volume under different horizons," Expert Systems with Applications, vol. 34, no. 4, pp. 3043-3054, 2008.

[46] A. M. Rather, V. N. Sastry, and A. Agarwal, "Stock market prediction and Portfolio selection models: a survey," Opsearch, vol. 54, no. 3, pp. 558-579, 2017.

[47] O. Chatrabgoun, A. Hosseinian-Far, V. Chang, N. G. Stocks, and A. Daneshkhah, "Approximating non-Gaussian Bayesian networks using minimum information vine model with applications in financial modelling," Journal of Computational Science, vol. 24, pp. 266-276, 2018.

[48] S. Emerson, R. Kennedy, L. O. Shea, and J. O. Brien, "Trends and applications of machine learning in quantitative finance," in Proceedings of the 8th International Conference on Economics and Finance Research, Lyon, France, June 2019.

[49] C. H. Fajardo-Toro, J. Mula, and R. Poler, "Adaptive and hybrid forecasting models-a review," in Engineering Digital Transformation, pp. 315-322, Springer, Berlin, Germany, 2018.

[50] T. Kaya and B. Erkut, "Tacit knowledge for strategic advantage: social media use of employees in the financial sector," in Proceedings of the 18th European Conference on Knowledge Management (ECKM 2017), pp. 516-523, Barcelona, Spain, September 2017.

[51] T. Poddig and H. Rehkugler, "A "world" model of integrated financial markets using artificial neural networks," Neurocomputing, vol. 10, no. 3, pp. 251-273, 1996.

[52] A. Parisi and F. Parisi, "Predictive models of logic and fuzzy logic in stock market index of the United States," Trimestre Economico, vol. 73, no. 290, pp. 265-288, 2006.

[53] N. O'Connor and M. G. Madden, "A neural network approach to predicting stock exchange movements using external factors," Knowledge-Based Systems, vol. 19, no. 5, pp. 371-378, 2006.

[54] M. F. Abbod, F. C. Hamdy, D. A. Linkens, and J. W. Catto, "Predictive modeling in cancer: where systems biology meets the stock market," Expert Review of Anticancer Therapy, vol. 9, no. 7, pp. 867-870, 2009. 
[55] Z. Liao and J. Wang, "Forecasting model of global stock index by stochastic time effective neural network," Expert Systems with Applications, vol. 37, no. 1, pp. 834-841, 2010.

[56] F. Liu and J. Wang, "Fluctuation prediction of stock market index by Legendre neural network with random time strength function," Neuro Computing, vol. 83, pp. 12-21, 2012.

[57] H. Y. Mo and J. Wang, "Volatility degree forecasting of stock market by stochastic time strength neural network," Mathematical Problems in Engineering, vol. 2013, Article ID 436795, 2013.

[58] H. V. Pham, T. Cao, I. Nakaoka, E. W. Cooper, and K. Kamei, "A proposal of hybrid kansei-som model for stock market investment," International Journal of Innovative Computing Information and Control, vol. 7, no. 5B, pp. 2863-2880, 2011.

[59] M. Qiu, Y. Song, and F. Akagi, "Application of artificial neural network for the prediction of stock market returns: the case of the Japanese stock market," Chaos, Solitons \& Fractals, vol. 85, pp. 1-7, 2016.

[60] Q. A. Chen and C. D. Li, "Comparison of forecasting performance of AR, STAR and ANN models on the Chinese stock market index," in Advances in Neural Networks - Isnn 2006, Pt 3, Proceedings, vol. 3973, pp. 464-470, SpringerVerlag Berlin, Berlin, Germany, 2006.

[61] Y. K. Bao, Y. S. Lu, and J. L. Zhang, "Forecasting stock price by SVMs regression," in Artificial Intelligence: Methodology, Systems, and Applications, Proceedings, vol. 3192, pp. 295-303, Springer-Verlag Berlin, Berlin, Germany, 2004.

[62] H. F. Liu and J. Wang, "Integrating independent component analysis and principal component analysis with neural network to predict Chinese stock market," Mathematical Problems in Engineering, vol. 2019, 2011.

[63] A. J. Lin, P. J. Shang, G. C. Feng, and B. Zhong, "Application of empirical mode decomposition combined with k-nearest neighbors approach in financial time series forecasting," Fluctuation and Noise Letters, vol. 11, no. 2, 2012.

[64] J. Wang and J. Wang, "Forecasting stochastic neural network based on financial empirical mode decomposition," Neural Networks, vol. 90, pp. 8-20, 2017.

[65] X. Liang, "Neural network method to predict stock price movement based on stock information entropy," in Advances in Neural Networks-Isnn 2006, Pt 3, Proceedings, vol. 3973, pp. 442-451, Springer-Verlag Berlin, Berlin, Germany, 2006.

[66] N. Li, X. Liang, X. Li, C. Wang, and D. D. Wu, "Network environment and financial risk using machine learning and sentiment analysis," Human and Ecological Risk Assessment: An International Journal, vol. 15, no. 2, pp. 227-252, 2009.

[67] X. Liang, "Impacts of Internet stock news on stock markets based on neural networks," in Advances in Neural Networks Isnn 2005, Pt 2, Proceedings, vol. 3497, pp. 897-903, Springer-Verlag Berlin, Berlin, Germany, 2005.

[68] H. Rehkugler and T. Poddig, "Artificial neural networks in financial analysis-A new approach to forecast movements of stocks, indexes and currencies," Wirtschaftsinformatik, vol. 33, no. 5, pp. 365-374, 1991.

[69] B. Freisleben, "Stock-market prediction with backpropagation networks," Lecture Notes in Artificial Intelligence, vol. 604, pp. 451-460, 1992.

[70] D. W. Salt, N. Yildiz, D. J. Livingstone, and C. J. Tinsley, "The use of artificial neural networks in Qsar," Pesticide Science, vol. 36, no. 2, pp. 161-170, 1992.
[71] Y. Yoon, G. Swales, and T. M. Margavio, "A comparison of discriminant analysis versus artificial neural networks," The Journal of the Operational Research Society, vol. 44, no. 1, pp. 51-60, 1993.

[72] H. J. Kim, K. S. Shin, and K. Park, "Time delay neural networks and genetic algorithms for detecting temporal patterns in stock markets," in Advances in Natural Computation, Pt 1, Proceedings, vol. 3610, pp. 1247-1255, Springer-Verlag Berlin, Berlin, Germany, 2005.

[73] M. Khashei, S. Reza Hejazi, and M. Bijari, "A new hybrid artificial neural networks and fuzzy regression model for time series forecasting," Fuzzy Sets and Systems, vol. 159, no. 7, pp. 769-786, 2008.

[74] A. Bohn, T. Güting, T. Mansmann, and S. Selle, "MoneyBee: aktienkursprognose mit künstlicher intelligenz bei hoher rechenleistung," Wirtschaftsinformatik, vol. 45, no. 3, pp. 325-333, 2003.

[75] L. Zhang, N. Liu, and P. Yu, "A novel instantaneous frequency algorithm and its application in stock index movement prediction," IEEE Journal of Selected Topics in Signal Processing, vol. 6, no. 4, pp. 311-318, 2012.

[76] O. Haroon and S. A. R. Rizvi, "COVID-19: media coverage and financial markets behavior-A sectoral inquiry," Journal of Behavioral and Experimental Finance, vol. 27, Article ID 100343, 2020.

[77] M. C. R. de C. Ferreira, V. A. Sobreiro, H. Kimura, and F. L. de M. Barboza, "A systematic review of literature about finance and sustainability," Journal of Sustainable Finance \& Investment ISSN, vol. 6, no. 2, pp. 112-147, 2016.

[78] C. J. C. Jabbour, "Environmental training in organisations: from a literature review to a framework for future research," Resources, Conservation and Recycling, vol. 74, pp. 144-155, 2013.

[79] M. Lage Junior and M. Godinho Filho, "Variations of the kanban system: literature review and classification," International Journal of Production Economics, vol. 125, no. 1, pp. 13-21, 2010.

[80] S. Seuring, "A review of modeling approaches for sustainable supply chain management," Decision Support Systems, vol. 54, no. 4, pp. 1513-1520, 2013.

[81] M. J. Rezaee, M. Jozmaleki, and M. Valipour, "Integrating dynamic fuzzy C-means, data envelopment analysis and artificial neural network to online prediction performance of companies in stock exchange," Physica A-Statistical Mechanics and Its Applications, vol. 489, pp. 78-93, 2018.

[82] A. K. Rout, P. K. Dash, R. Dash, and R. Bisoi, "Forecasting financial time series using a low complexity recurrent neural network and evolutionary learning approach," Journal of King Saud University-Computer and Information Sciences, vol. 29, no. 4, pp. 536-552, 2017.

[83] B. Wu and T. Duan, "A performance comparison of neural networks in forecasting stock price trend," International Journal of Computational Intelligence Systems, vol. 10, no. 1, pp. 336-346, 2017.

[84] P. Nystrup, H. Madsen, and E. Lindström, "Dynamic portfolio optimization across hidden market regimes," Quantitative Finance, vol. 18, pp. 1-13, 2017.

[85] Z. Tracking, "Economic model predictive control with zone tracking," Mathematics, vol. 6, no. 65, pp. 1-19, 2018.

[86] F. Herzog, G. Dondi, and H. P. Geering, "Stochastic model predictive control and portfolio optimization," International Journal of Theoretical and Applied Finance, vol. 10, no. 02, pp. 203-233, 2007. 
[87] Y. Yamada and J. A. Primbs, "Model predictive control for optimal pairs trading portfolio with gross exposure and transaction cost constraints," Asia-Pacific Financial Markets, 2017.

[88] V. Dombrovskii and T. Obedko, "Feedback predictive control strategies for investment in the financial market with serially correlated returns subject to constraints and trading costs," Optimal Control Applied Methodology, pp. 1-14, 2017.

[89] A. Mochón, D. Quintana, Y. Sáez, and P. Isasi, "Soft computing techniques applied to finance," Applied Intelligence, vol. 29, no. 2, pp. 111-115, 2008.

[90] L. A. Zadeh, "Fuzzy logic, neural networks, and soft computing," Communications of the ACM, vol. 37, no. 3, pp. 77-84, 1994.

[91] S. P. Das and S. Padhy, "A new hybrid parametric and machine learning model with homogeneity hint for European-style index option pricing," Neural Computing and Applications, vol. 28, no. 12, pp. 4061-4077, 2017.

[92] C. Jayne, A. Lanitis, and C. Christodoulou, "Neural network methods for one-to-many multi-valued mapping problems," Neural Computing and Applications, vol. 20, no. 6, pp. 775-785, 2011.

[93] K.-j. Kim and W. B. Lee, "Stock market prediction using artificial neural networks with optimal feature transformation," Neural Computing and Applications, vol. 13, no. 3, pp. 255-260, 2004.

[94] Z. G. Qun, L. Y. Xu, and G. W. Zhang, "LSTM neural network with emotional analysis for prediction of stock price," Engineering Letters, vol. 25, no. 2, pp. 167-175, 2017.

[95] S. C. Nayak, B. B. Misra, and H. S. Behera, "Artificial chemical reaction optimization of neural networks for efficient prediction of stock market indices," Ain Shams Engineering Journal, vol. 8, no. 3, pp. 371-390, 2017.

[96] A. Bahrammirzaee, "A comparative survey of artificial intelligence applications in finance: artificial neural networks, expert system and hybrid intelligent systems," Neural Computing and Applications, vol. 19, pp. 1165-1196, 2010.

[97] Y. Li, C. Wu, J. Liu, and P. Luo, "A combination prediction model of stock composite index based on artificial intelligent methods and multi-agent simulation," International Journal of Computational Intelligence Systems, vol. 7, no. 5, pp. 853-864, 2014.

[98] M. Inthachot, V. Boonjing, and S. Intakosum, "Artificial Neural Network and genetic algorithm hybrid intelligence for predicting Thai stock price index trend.pdf," Computational Intelligence and Neuroscience, 2016.

[99] D. K. Bebarta, B. Biswal, and P. K. Dash, "Polynomial based functional link artificial recurrent neural network adaptive system for predicting Indian stocks," International Journal of Computational Intelligence Systems, vol. 8, no. 6, pp. 10041016, 2015.

[100] K. Menger-Anderson, "The ethics of digitally networked beings-towards data science," 2018.

[101] A. Ghandar, Z. Michalewicz, M. Schmidt, T.-D. To, and R. Zurbrugg, "Computational intelligence for evolving trading rules," IEEE Transactions on Evolutionary Computation, vol. 13, no. 1, pp. 71-86, 2009.

[102] R. Naranjo, J. Arroyo, and M. Santos, "Fuzzy modeling of stock trading with fuzzy candlesticks," Expert Systems with Applications, vol. 93, pp. 15-27, 2018.

[103] L. Y. Wei, T. L. Chen, and T. H. Ho, "A hybrid model based on adaptive-network-based fuzzy inference system to forecast Taiwan stock market," Expert Systems with Applications, vol. 38, no. 11, pp. 13625-13631, 2011.
[104] K. K. Ang and C. Quek, "Stock trading using RSPOP: a novel rough set-based neuro-fuzzy approach," IEEE Transactions on Neural Networks, vol. 17, no. 5, pp. 1301-1315, 2006.

[105] S. D. Bekiros, "Sign prediction and volatility dynamics with hybrid neurofuzzy approaches," IEEE Transactions on Neural Networks, vol. 22, no. 12, pp. 2353-2362, 2011.

[106] J. Komlos and B. Suessmuth, Empirische Ökonomie-Eine Einführung in Methoden und Anwendungen, Springer, Berlin, Germany, 2010, https://www.springer.com/de/book/ 9783642017049.

[107] A. Karathanasopoulos, "Modelling and trading the English stock market with novelty optimization techniques," Economics and Business Letters, vol. 5, no. 2, pp. 50-57, 2016.

[108] R. Y. M. Li, S. Fong, and K. W. S. Chong, "Forecasting the REITs and stock indices: group method of data handling neural network approach," Pacific Rim Property Research Journal, vol. 23, no. 2, pp. 123-160, 2017.

[109] X. Zhong and D. Enke, "A comprehensive cluster and classification mining procedure for daily stock market return forecasting," Neurocomputing, vol. 267, pp. 152-168, 2017.

[110] P. C. Chang, C. Y. Fan, and C. H. Liu, "Integrating a piecewise linear representation method and a neural network model for stock trading points prediction," IEEE Transactions on Systems Man and Cybernetics Part C-Applications and Reviews, vol. 39, no. 1, pp. 80-92, 2009.

[111] M. Kheradmandi and P. Mhaskar, "Data driven economic model predictive control," Mathematics, vol. 6, no. 51, pp. 1-17, 2018.

[112] T. Trimborn, L. Pareschi, and M. Frank, "Portfolio optimization and model predictive control: a kinetic approach," Discrete \& Continuous Dynamical Systems - B, vol. 24, no. 11, pp. 6209-6238, 2019.

[113] D. Zantedeschi, P. Damien, and N. G. Polson, "Predictive macro-finance with dynamic partition models," Journal of the American Statistical Association, vol. 106, no. 494, pp. 427-439, 2011.

[114] L. Sanzogni, G. Guzman, and P. Busch, "Artificial intelligence and knowledge management: questioning the tacit dimension," Prometheus, vol. 35, no. 1, pp. 37-56, 2017.

[115] M. Dong and X.-S. Zhou, "Knowledge discovery in corporate events by neural network rule extraction," Applied Intelligence, vol. 29, no. 2, pp. 129-137, 2008.

[116] C.-H. Liu, J. S. Wang, and C.-W. Lin, "The concepts of big data applied in personal knowledge management," Journal of Knowledge Management, vol. 21, no. 1, pp. 213-230, 2017.

[117] B. Erkut, "From digital government to digital governance: are we there yet?" Sustainability, vol. 12, no. 3, 2020.

[118] S. I. Ao, "Automating stock prediction with neural network and evolutionary computation," in Intelligent Data Engineering and Automated Learning, vol. 2690, pp. 203-210, Springer-Verlag Berlin, Berlin, Germany, 2003.

[119] Q. Cao, M. E. Parry, and K. B. Leggio, "The three-factor model and artificial neural networks: predicting stock price movement in China," Annals of Operations Research, vol. 185, no. 1, pp. 25-44, 2011.

[120] A.-S. Chen, M. T. Leung, and H. Daouk, “Application of neural networks to an emerging financial market: forecasting and trading the Taiwan Stock Index," Computers \& Operations Research, vol. 30, no. 6, pp. 901-923, 2003.

[121] E. Constantinou, R. Georgiades, A. Kazandjian, and G. P. Kouretas, "Regime switching and artificial neural network forecasting of the cyprus stock exchange daily returns," International Journal of Finance \& Economics, vol. 11, no. 4, pp. 371-383, 2006. 
[122] J. H. Ma and L. X. Liu, "Multivariate nonlinear analysis and prediction of Shanghai stock market," Discrete Dynamics in Nature and Society, vol. 2008, Article ID 526734, 2008.

[123] M. M. Mostafa, "Forecasting stock exchange movements using neural networks: empirical evidence from Kuwait," Expert Systems with Applications, vol. 37, no. 9, pp. 6302-6309, 2010.

[124] K. J. Oh, T. Y. Kim, H. Y. Lee, and H. Lee, "Using neural networks to support early warning system for financial crisis forecasting," in Ai 2005: Advances in Artificial Intelligence, vol. 3809, pp. 284-296, Springer-Verlag Berlin, Berlin, Germany, 2005.

[125] H. S. Basavegowda, G. Dagnew, and G. Dagnew, "Deep learning approach for microarray cancer data classification," CAAI Transactions on Intelligence Technology, vol. 5, no. 1, pp. 22-33, 2020.

[126] N. N. Das, K. Naresh, K. Manjit, K. Vijay, and S. Dilbag, "Automated deep transfer learning-based approach for detection of COVID-19 infection in chest X-rays," Irbm, 2020.

[127] A. Jaiswal, N. Gianchandani, D. Singh, V. Kumar, and M. Kaur, "Classification of the COVID-19 infected patients using DenseNet201 based deep transfer learning," Journal of Biomolecular Structure and Dynamics, pp. 1-8, 2020.

[128] S. Osterland and J. Weber, "Analytical analysis of singlestage pressure relief valves," International Journal of Hydromechatronics, vol. 2, no. 1, pp. 32-53, 2019.

[129] R. Wang, H. Yu, G. Wang, G. Zhang, and W. Wang, "Study on the dynamic and static characteristics of gas static thrust bearing with micro-hole restrictors," International Journal of Hydromechatronics, vol. 2, no. 3, pp. 189-202, 2019.

[130] T. Wiens, "Engine speed reduction for hydraulic machinery using predictive algorithms," International Journal of Hydromechatronics, vol. 2, no. 1, pp. 16-31, 2019.

[131] M. H. F. Zarandi, B. Rezaee, I. B. Turksen, and E. Neshat, “A type-2 fuzzy rule-based expert system model for stock price analysis," Expert Systems with Applications, vol. 36, no. 1, pp. 139-154, 2009.

[132] A. Azadeh, M. Aryaee, M. Zarrin, and M. Saberi, "A novel performance measurement approach based on trust context using fuzzy T-norm and S-norm operators: the case study of energy consumption," Energy Exploration \& Exploitation, vol. 34, no. 4, pp. 561-585, 2016.

[133] D. Singh, V. Kumar, Vaishali, and M. Kaur, "Classification of COVID-19 patients from chest CT images using multi-objective differential evolution-based convolutional neural networks," European Journal of Clinical Microbiology \& Infectious Diseases, vol. 39, no. 7, pp. 1379-1389, 2020.

[134] S. Ghosh, P. Shivakumara, P. Roy, U. Pal, and T. Lu, "Graphology based handwritten character analysis for human behaviour identification," CAAI Transactions on Intelligence Technology, vol. 5, no. 1, pp. 55-65, 2020.

[135] A. Girdhar, H. Kapur, V. Kumar, M. Kaur, D. Singh, and R. Damasevicius, "Effect of COVID-19 outbreak on urban health and environment," Air Quality, Atmosphere \& Health, pp. 1-9, 2020.

[136] B. Gupta, M. Tiwari, and S. Singh Lamba, "Visibility improvement and mass segmentation of mammogram images using quantile separated histogram equalisation with local contrast enhancement," CAAI Transactions on Intelligence Technology, vol. 4, no. 2, pp. 73-79, 2019.

[137] R. Singh and S. Srivastava, "Stock prediction using deep learning," Multimedia Tools and Applications, vol. 76, no. 18, pp. 18569-18584, 2017.

[138] M. Alizadeh, R. Rada, F. Jolai, and E. Fotoohi, "An adaptive neuro-fuzzy system for stock portfolio analysis,"
International Journal of Intelligent Systems, vol. 26, no. 2, pp. 99-114, 2011.

[139] G. S. Atsalakis, E. M. Dimitrakakis, and C. D. Zopounidis, "Elliott Wave Theory and neuro-fuzzy systems, in stock market prediction: the WASP system," Expert Systems with Applications, vol. 38, no. 8, pp. 9196-9206, 2011.

[140] A. Keles, M. Kolcak, and A. Keles, "The adaptive neuro-fuzzy model for forecasting the domestic debt," Knowledge-Based Systems, vol. 21, no. 8, pp. 951-957, 2008.

[141] L. Y. Wei, "An expanded Adaptive Neuro-Fuzzy Inference System (ANFIS) model based on AR and causality of multination stock market volatility for TAIEX forecasting," African Journal of Business Management, vol. 5, no. 15, pp. 6377-6387, 2011.

[142] G. Armano, M. Marchesi, and A. Murru, "A hybrid geneticneural architecture for stock indexes forecasting," Information Sciences, vol. 170, no. 1, pp. 3-33, 2005.

[143] Q. Cao and M. E. Parry, "Neural network earnings per share forecasting models: a comparison of backward propagation and the genetic algorithm," Decision Support Systems, vol. 47, no. 1, pp. 32-41, 2009.

[144] C.-H. Cheng, T.-L. Chen, and L.-Y. Wei, "A hybrid model based on rough sets theory and genetic algorithms for stock price forecasting," Information Sciences, vol. 180, no. 9, pp. 1610-1629, 2010.

[145] A. Esfahanipour and S. Mousavi, "A genetic programming model to generate risk-adjusted technical trading rules in stock markets," Expert Systems with Applications, vol. 38, no. 7, pp. 8438-8445, 2011.

[146] Y. K. Kwon and B. R. Moon, "A hybrid neurogenetic approach for stock forecasting," IEEE Transactions on Neural Networks, vol. 18, no. 3, pp. 851-864, 2007.

[147] J. Mandziuk and M. Jaruszewicz, "Neuro-genetic system for stock index prediction," Journal of Intelligent \& Fuzzy Systems, vol. 22, no. 2-3, pp. 93-123, 2011.

[148] T. Z. Tan, C. Quek, and G. S. Ng, "Biological brain-inspired genetic complementary learning for stock market and bank failure prediction," Computational Intelligence, vol. 23, no. 2, pp. 236-261, 2007.

[149] V.S. Desai and R. Bharati, "The efficacy of neural networks in predicting returns on stock and bond indices," Decision Sciences, vol. 29, no. 2, pp. 405-423, 1998.

[150] S. Amornwattana, D. Enke, and C. H. Dagli, "A hybrid option pricing model using a neural network for estimating volatility," International Journal of General Systems, vol. 36, no. 5, pp. 558-573, 2007.

[151] W. Huang, S. Y. Wang, L. Yu, Y. K. Bao, and L. Wang, "A new computational method of input selection for stock market forecasting with neural networks," in Computational Science - Iccs 2006, Pt 4, Proceedings, vol. 3994, pp. 308-315, Springer-Verlag Berlin, Berlin, Germany, 2006.

[152] M. Kohler and A. Krzyżak, "Pricing of American options in discrete time using least squares estimates with complexity penalties," Journal of Statistical Planning and Inference, vol. 142, no. 8, pp. 2289-2307, 2012.

[153] P. R. Lajbcygier and J. T. Connor, "Improved option pricing using artificial neural networks and bootstrap methods," International Journal of Neural Systems, vol. 08, no. 04, pp. 457-471, 1997.

[154] H. Ince and T. B. Trafalis, "Kernel principal component analysis and support vector machines for stock price prediction," Iie Transactions, vol. 39, no. 6, pp. 629-637, 2007. 
[155] D. Olson and C. Mossman, "Neural network forecasts of Canadian stock returns using accounting ratios," International Journal of Forecasting, vol. 19, no. 3, pp. 453-465, 2003.

[156] J. Patel, S. Shah, P. Thakkar, and K. Kotecha, "Predicting stock and stock price index movement using Trend Deterministic Data Preparation and machine learning techniques," Expert Systems with Applications, vol. 42, no. 1, pp. 259-268, 2015.

[157] A. M. Safer, "The application of neural networks to predict abnormal stock returns using insider trading data," Applied Stochastic Models in Business and Industry, vol. 18, no. 4, pp. 381-389, 2002.

[158] I. Yildirim, S. Ozsahin, and K. C. Akyuz, "Prediction of the financial return of the paper sector with artificial neural networks," Bioresources, vol. 6, no. 4, pp. 4076-4091, 2011.

[159] S. Yümlü, F. S. Gürgen, and N. Okay, "A comparison of global, recurrent and smoothed-piecewise neural models for Istanbul stock exchange (ISE) prediction," Pattern Recognition Letters, vol. 26, no. 13, pp. 2093-2103, 2005. 